\title{
Uniportal bilateral video-assisted thoracoscopic extended thymectomy for myasthenia gravis: A case report
}

Francesco Paolo Caronia, MD, ${ }^{\mathrm{a}}$ Alfonso Fiorelli, MD, PhD, ${ }^{\mathrm{b}}$ Mario Santini, MD, ${ }^{\mathrm{b}}$ and Salvatore Cottone, $\mathrm{MD},{ }^{\mathrm{C}}$ Catania, Naples, and Palermo, Italy

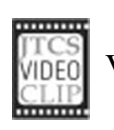

Video clip is available online.

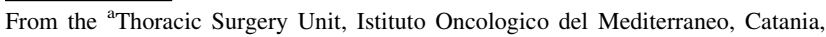
Italy; the ${ }^{\mathrm{b}}$ Thoracic Surgery Unit, Second University of Naples, Naples, Italy; and the ${ }^{\mathrm{c}}$ Neurology Unit, Azienda Ospedaliera Ospedali Riuniti Villa SofiaCervello, Palermo, Italy.

Disclosures: Authors have nothing to disclose with regard to commercial support. F.P.C. and A.F. have contributed equally to the preparation of this article.

Received for publication Jan 2, 2015; revisions received Feb 12, 2015; accepted for publication March 28, 2015; available ahead of print May 1, 2015.

Address for reprints: Alfonso Fiorelli, MD, PhD, Thoracic Surgery Unit, Second University of Naples, Piazza Miraglia, 2, I-80138 Naples, Italy (E-mail: alfonso. fiorelli@unina2.it).

J Thorac Cardiovasc Surg 2015;150:e1-3

$0022-5223 / \$ 36.00$

Copyright (C 2015 by The American Association for Thoracic Surgery

http://dx.doi.org/10.1016/j.jtcvs.2015.03.063
Video-assisted thoracoscopic extended thymectomy has been shown to be a safe and feasible technique in patients with myasthenia gravis and is a preferable surgical option to median sternotomy because of its better cosmetic results, lessened postoperative pain, and reduction in hospital stay. ${ }^{1}$ We report a development of video-assisted thoracoscopic extended thymectomy as the complete resection of thymus with a uniportal bilateral thoracoscopic approach in a patient with hyperplastic thymus and myasthenia gravis.

\section{CLINICAL SUMMARY}

A 39-year-old woman with hyperplastic thymus and myasthenia gravis was referred to our institution for surgery. Plasmapheresis was performed preoperatively

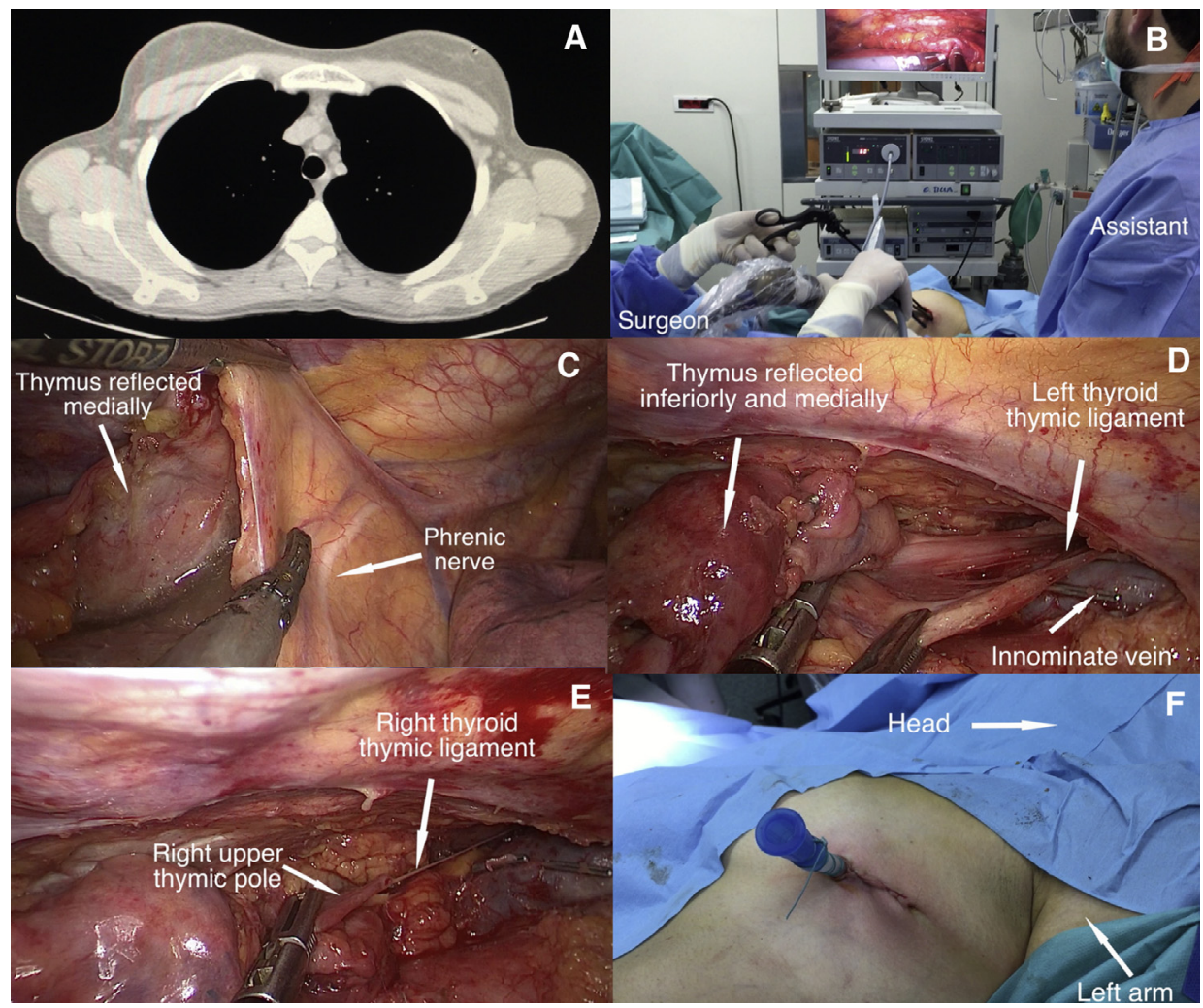

FIGURE 1. A, The chest computed tomography scan showed a $1.5-\mathrm{cm}$ mediastinal thymic mass. B, The patient was placed in the right lateral decubitus position, and the surgeon and the assistant were positioned on the posterior side. C, After identification of the left phrenic nerve, initial dissection was begun with the Ultracision harmonic scalpel running along the border of the left phrenic nerve. D, The thymus was retracted inferiorly and medially, and the innominate vein was skeletonized. E, The complete mobilization of thymus allowed the exposition of the both thyroid-thymic ligaments. F, After completion of the leftward dissection, a single chest tube was inserted through the intercostal incision. 


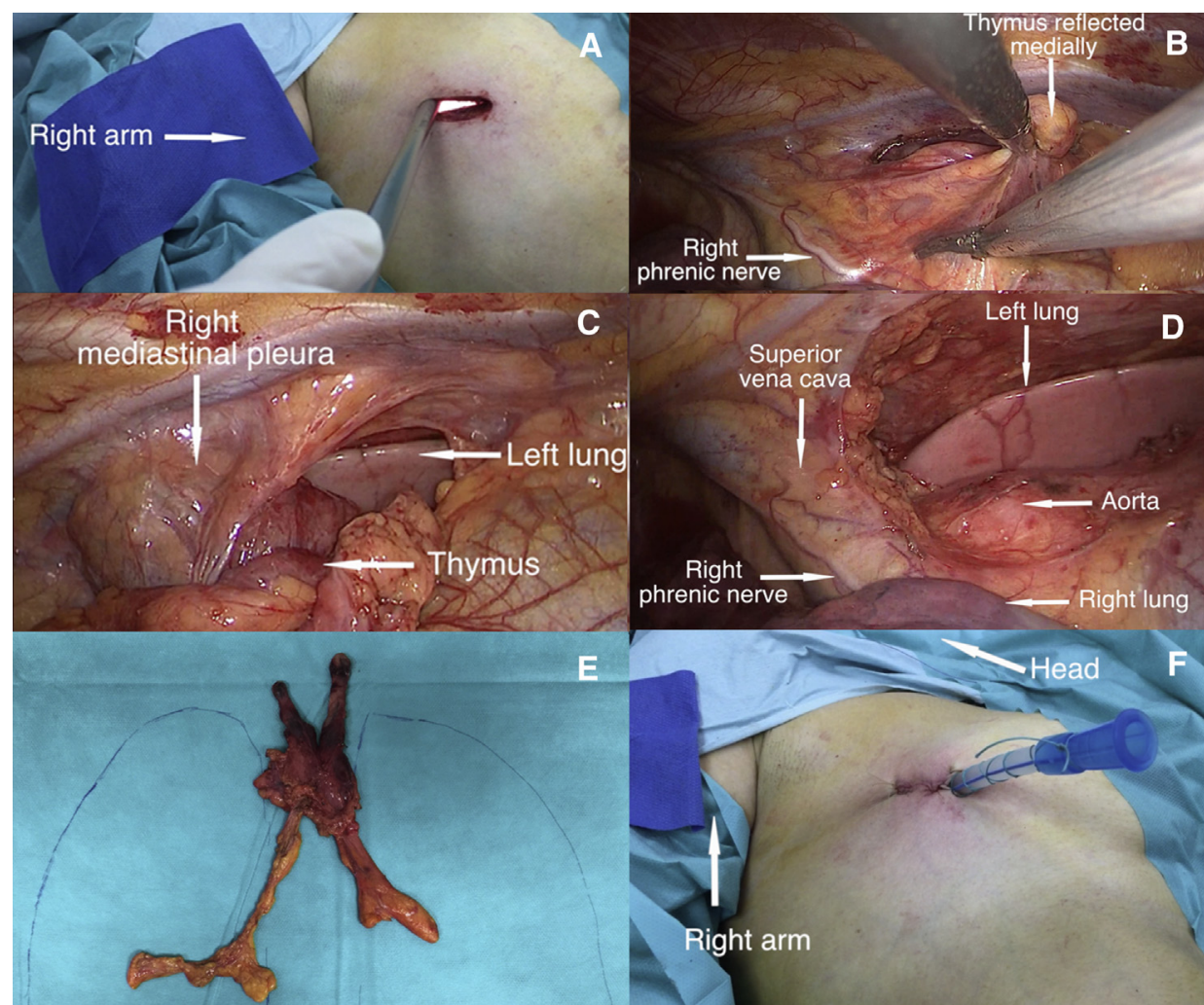

FIGURE 2. A, A 4-cm length incision was performed within the fourth intercostal space. B, The mediastinal pleura was dissected along the right phrenic nerve. $\mathrm{C}$ and $\mathrm{D}$, The en bloc dissection of thymus and perithymic and pericardiophrenic fatty tissue was achieved. E, The specimen. F, Closure of right incision with a chest drain.

through a period of 5 days. The patient was placed in the $60^{\circ}$ right lateral decubitus position as previously described. ${ }^{2}$ The ipsilateral arm was wrapped in a sterile stockinet and maintained parallel to the body. The patient underwent as the first step a left uniportal thoracoscopic approach through a 4-cm incision in the fourth interspace without rib spreading and without direct visualization of pleural cavity. We placed the $30^{\circ}$ camera in the posterior part of the skin incision, with conventional thoracoscopic instruments working below. After exploring the pleural cavity, we started the dissection inferiorly by incising the mediastinal pleura along the anterior border of the phrenic nerve, and we carried out thymic dissection cranially with a harmonic scalpel (Ultracision Harmonic; Johnson \& Johnson, New Brunswick, NJ). We mobilized the body of the thymus to expose thymic veins, which were sectioned between endoscopic clips. The innominate vein was skeletonized. We dissected the upper thymic poles from the surrounding fat tissue above the innominate vein and carefully pulled them down to obtain their complete mobilization until the thyroid-thymic ligaments became visible. The mediastinal fat was completely dissected from phrenic nerve, innominate vein, aortopulmonary window, aortocaval groove, and pericardiophrenic angle. After completion of the leftward dissection, we opened the contralateral pleura to push the specimen into the right pleural cavity. A chest tube was inserted through the incision. The left side procedure is illustrated in Figure 1. We then placed the patient in the left lateral decubitus position. The patient had a right uniportal thoracoscopic approach through a 4-cm incision in the fourth intercostal space in the same way as for the left side. We completed rightward thymic and pericardiophrenic fatty tissue dissection. The specimen was retrieved with an endoscopic specimen retrieval bag through the same incision, and a chest tube was placed through the incision. The en bloc dissection of thymus and perithymic and pericardiophrenic fatty tissue was achieved without sternal retractors through $4-\mathrm{cm}$ bilateral incisions. The right side procedure is illustrated in Figure 2. The overall surgical time was 150 minutes. The patient was discharged from the hospital on postoperative day 4. Pathologic examination revealed thymus hyperplasia. Six months later, no recurrence was found. Video 1 demonstrates the main steps of the operation.

\section{DISCUSSION}

Video-assisted thoracoscopic extended thymectomy is a widely accepted therapeutic approach for the integrated management of myasthenia gravis. Since the first report 
by Novellino and colleagues, ${ }^{3}$ several video-assisted thoracoscopic extended thymectomy procedures with varying numbers of port incisions have been proposed, according to the experience and the preference of surgeons. The uniportal thoracoscopic approach was described initially by Rocco and associates ${ }^{4}$ in 2004 for minor thoracic and pulmonary procedures. Since then, it has been used for other more complex procedures, including lobectomy, pneumonectomy, and bronchoplastic resection. During video-assisted thoracoscopic extended thymectomy, multiple port incisions force the surgeon to an unnatural eye-hand coordination relative to what must be done in open surgery. In addition, articulating graspers and endostaplers contribute to avoid interference of the thoracoscope and instrumentation. ${ }^{5}$ Conversely, a uniportal approach allows the maximal exposure of the anterior mediastinum that is crucial for resection of thymus and facilitates the view of cardiophrenic space, an area not always easily accessible, for performing a complete resection of mediastinal fat. In addition, through the same access the superior horns of the thymus can easily be pulled down, with complete exposure of innominate veins. All surgical dissection and the complete clearance of the mediastinal fat were achieved with the harmonic scalpel, which was also used for the division of small vessels (the larger vessels were endoscopically ligated and divided).

In conclusion, uniportal bilateral thoracoscopic extended thymectomy is a feasible procedure and may be a valid development of video-assisted thoracoscopic extended thymectomy. Obviously, our impression should be validated by further larger studies in terms of reproducibility and clinical results.

\section{References}

1. Shiono H, Kadota Y, Hayashi A, Okumura M. Comparison of outcomes after extended thymectomy for myasthenia gravis: bilateral thoracoscopic approach versus sternotomy. Surg Laparosc Endosc Percutan Tech. 2009;19: 424-7.

2. Caronia F, Fiorelli A, Monte AL. Bilateral thoracoscopic thymectomy using a novel positioning system. Asian Cardiovasc Thorac Ann. 2014;22:1135-7.

3. Novellino L, Longoni M, Spinelli L, Andretta M, Cozzi M, Faillace G, et al. "Extended" thymectomy without sternotomy, performed by cervicotomy and thoracoscopic technique in the treatment of myasthenia gravis. Int Surg. 1994; 79:378-81.

4. Rocco G, Martin-Ucar A, Passera E. Uniportal VATS wedge pulmonary resections. Ann Thorac Surg. 2004;77:726-8.

5. Rocco G. VATS and Uniportal VATS: a glimpse into the future. $J$ Thorac Dis 2013;5(Suppl 3):S174.

\title{
Pleurectomy and decortication for metastatic renal cell carcinoma
}

\author{
Aaron Bettenhausen, BS, ${ }^{\mathrm{a}}$ Masatsugu Hamaji, MD, ${ }^{\mathrm{b}}$ Bryan M. Burt, MD, ${ }^{\mathrm{c}}$ and Syed Osman Ali, MD, ${ }^{\mathrm{a}, \mathrm{d}}$ \\ Grand Forks, ND, Kyoto, Japan, and Houston, Tex
}

Pleurectomy and decortication is traditionally indicated for the resection of primary pleural tumors, such as malignant pleural mesothelioma. It is less commonly used for resection of metastatic disease. We present a case of pleurectomy and decortication for metastatic renal cell carcinoma (RCC) confined to the pleural space.

\footnotetext{
From the a Department of Surgery, University of North Dakota School of Medicine and Health Sciences, Grand Forks, ND; the ${ }^{\mathrm{b}}$ Department of Thoracic Surgery, Kyoto University Hospital, Kyoto, Japan; the ${ }^{\mathrm{c}}$ Department of General Thoracic Surgery, Baylor College of Medicine, Houston, Tex; and the ${ }^{\mathrm{d}}$ Department of Cardiovascular and Thoracic Surgery, Altru Hospital, Grand Forks, ND.

Disclosures: Authors have nothing to disclose with regard to commercial support.

Received for publication April 7, 2015; revisions received April 19, 2015; accepted for publication May 2, 2015.

Address for reprints: Aaron Bettenhausen, BS, 2961 24th Ave S No. 204, Grand

Forks, ND 58201 (E-mail: aaron.b.bettenhausen@my.und.edu).

J Thorac Cardiovasc Surg 2015;150:e3-5

$0022-5223 / \$ 36.00$

Copyright (C) 2015 by The American Association for Thoracic Surgery

http://dx.doi.org/10.1016/j.jtcvs.2015.05.007
}

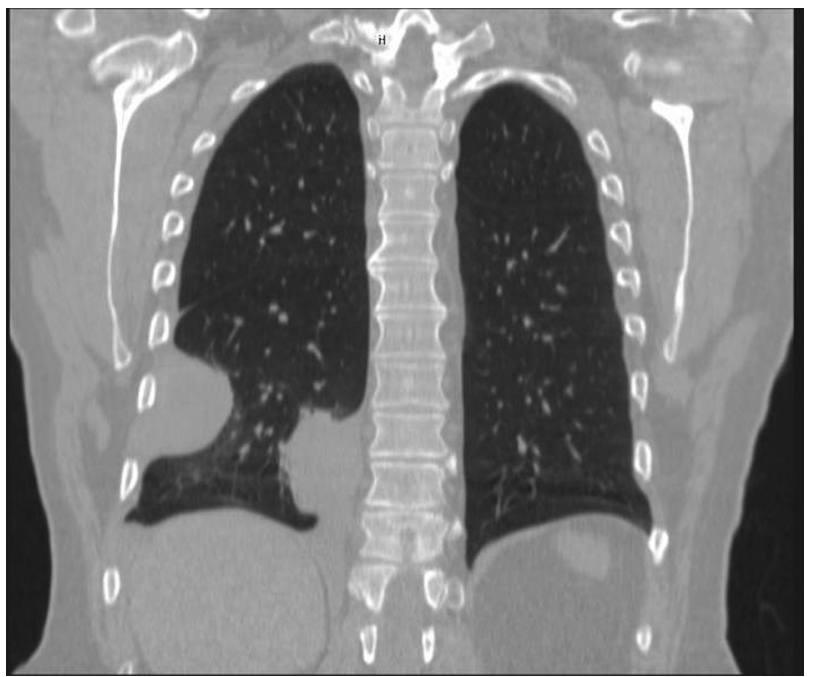

FIGURE 1. Chest computed tomography illustrating multiple pleuralbased masses. 